\title{
A casa [própria] alugada: questões da política pública habitacional
}

\author{
Ana Cristina da Silva Araujo \\ Arquiteta e urbanista, professora substituta da Faculdade de \\ Arquitetura, Artes e Comunicação-UNESP/Bauru, Av. Eng. Luiz \\ Edmundo Carrijo Coube, n 14-01, CEP 17033-360, Vargem Lim- \\ pa, Bauru, São Paulo, (14) 3103-6000, ana.crisaraujo@ig.com.br
}

\begin{abstract}
Resumo
O presente artigo trata do arrendamento residencial como possibilidade de diminuição do déficit habitacional brasileiro, discutindo os conceitos presentes no paradigma da casa própria e a contribuição de pesquisa empírica realizada no Residencial Cavalari, em Marília/SP, como base para compreensão do rompimento desta construção social arraigada no ideário da população brasileira, em face da expressiva difusão do Programa de Arrendamento Residencial.
\end{abstract}

Palavras-chave: arrendamento residencial, locação social, política pública habitacional.

${ }^{1}$ Música "Casa" de autoria de Toni Garrido, Bino, Da Gama e Lazão, integrantes da banda Cidade Negra, gravada no CD Sobre todas as forças. Sony Music, 1994

É seu único lugar no mundo que é seu abrigo, a sua casa que traz a liberdade em clima de felicidade. Onde pode ficar nu. Onde pode ficar. Onde pode ficar nu. E é tão difícil arrumar isso pra gente... Não há vitória quando a luta não é justa, mas só a relutância por esse mundo melhor é que nos traz a resposta, e qual é o resultado disso? Casa, casa, casa. Toda família precisa de um lar, Brasil duro é o Brasil, utopia, bem negado. Está difícil, mas não canso de lutar: minha casa, meu casulo então meu habitat.' (GARRIDO et all, 1994)

s palavras musicadas em ritmo de reagge retratam a concepção que a maioria dos brasileiros tem da casa, primeiramente como abrigo, que protege, acolhe, resguarda, constituindo um espaço singular, único, que confere proteção entre paredes, fechada e coberta. Ao mesmo tempo instaura o sentimento de liberdade, sendo um espaço em que o cidadão se sente livre e se permite ficar, atribuindo à casa a qualidade de lugar onde ele permanece, se sente à vontade e livre. Em outro plano, expõe o entendimento de que somente através da luta, justa, em que se obtém a vitória, é que se faz merecedor do abrigo. A casa então significa um objeto que se consegue através de luta permanente, dignificando a conquista. A vitória, neste caso, é fruto de um grande esforço empreendido diante de uma condição de dureza, de um Brasil duro com os que lutam, que impõe à obtenção da casa a condição de utopia diante de uma necessidade familiar negada.

A "casa do reagge" concentra conceitos da política pública habitacional praticada nas últimas décadas, ao enquadrar todos os programas na modalidade de financiamento voltados para a aquisição de lotes urbanizados, para a construção e aquisição de imóveis novos ou usados, não apresentando até o ano de 1999 nenhuma outra modalidade que representasse a diversificação no modelo de acesso à moradia para a população brasileira.

Quando se vislumbra a possibilidade do rompimento do paradigma da casa própria face ao modelo de 
${ }^{2}$ A Lei Federal n. 11.474, de 2007 prevê a antecipação da aquisição do imóvel arrendado.

3 Para esta questão ver MANTEGA, Guido (1984). "A Economia Política Brasileira," São Paulo/Rio de Janeiro, Polis/Nozes. arrendamento, que rompe o padrão, mas não totalmente, uma vez que original e conceitualmente projeta a aquisição como uma possibilidade, ainda originalmente, a longo prazo, e por determinações recentemente implantadas, a médio prazo, ${ }^{2}$ introduzse uma inquietação, que é parte da problemática habitacional da população de baixa renda, e que consiste na constatação de que uma parte desta população precisa de um abrigo próprio, porque o que lhe serve como abrigo é dividido com outras famílias ou muitas vezes, é alugado, sendo propriedade de outro a quem é pago um preço alto. Outra parte desta população necessita primordialmente de um abrigo, porque o que the serve como abrigo não é digno, não oferece conforto, higiene, saúde, não tem água limpa, em sua porta corre o esgoto e frequentemente se desmancha na chuva.

Seja pela necessidade de desfazer a situação de coabitação, seja para cessar o pagamento de altos aluguéis, ou ainda, seja pela moradia imprópria, nos três casos expostos, independente da motivação, não necessariamente é relevante a posse deste abrigo, pois esta parte da população precisa simplesmente se abrigar, desfazendo a situação de coabitação, de submissão aos altos aluguéis impostos pelo mercado ou de habitar em áreas ou espaços impróprios.

Uma política habitacional considerada justa e eficiente deve atender a estas necessidades expostas e a tantas outras existentes, o que certamente está além das formas tradicionais de construção e aquisição de imóvel através de financiamento que, invariavelmente, exige uma capacidade de pagamento que se define pela equação resultante da renda familiar alcançada e da capacidade de comprometimento desta renda perante o imóvel pretendido, com resultado que repele a maior parte da população de baixa renda da maioria dos programas vigentes.

A disseminação do conceito da casa própria foi propagada ao longo de muitos anos e perpetuada por razões de ordens diversas, definindo uma política habitacional calcada na questão da propriedade, sendo que o espaço das cidades - o espaço urbano - representava o lugar de conflito entre as diferentes classes e seus diferentes interesses.
Desta forma, os habitantes da cidade, certamente os mais desfavorecidos, poderiam constituir uma força de instabilidade e ingovernabilidade permanentes, oferecendo risco para a organização política. Neste quadro em que o Estado assumiu o papel de articulador destes interesses e de certa forma mediador, ao mesmo tempo em que ator deste conflito; agindo na ocupação do solo urbano de forma que interessasse a ele próprio e logo alargando os interesses no favorecimento da classe detentora de poder e acumuladora de capital. O Estado agiu - e ainda hoje age - através de políticas públicas no provimento do que é necessidade básica, fora do investimento privado, com o objetivo de dar suporte ao desenvolvimento crescente das cidades, face ao também crescente processo de industrialização que estava em curso. ${ }^{3}$

De um lado, o regime de acumulação capitalista interferiu nas dinâmicas das relações e evidenciou os conflitos entre a classe dominante e a classe trabalhadora, que sentiu os efeitos exploratórios impostos pelo capitalismo. Evidentemente, este não é um fenômeno nacional, ainda que aqui tenha assumido feições próprias, mas como lembra David Harvey:

As pressões coletivas exercidas pelo Estado ou por outras instituições [...] aliadas ao exercício de poder de domínio de mercado pelas grandes corporações e outras instituições poderosas, afetam de modo vital a dinâmica do capitalismo. Essas pressões podem ser diretas (como a imposição de controles de salários e preços) ou indiretas (como propaganda subliminar que nos persuade a incorporar novos conceitos sobre nossas necessidades e desejos básicos na vida). (HARVEY, 1998, p. 118).

No caso do Brasil, a regulação do salário através da definição de um valor fixo constitui o salário mínimo. Porém ele serviu mais para corrigir alguns desvios de rumo do capitalismo, com a acumulação da força de trabalho, do que para melhorar as condições de vida dos trabalhadores. O valor do trabalho foi nivelado por baixo e a deterioração do salário logo surgiu. A população que já enfrentava problemas com os altos aluguéis praticados, conseqüentes do crescimento das cidades, desordenado e excludente, incorporando novos conceitos sobre suas necessidades e desejos básicos, vê na 
possibilidade da aquisição da casa própria a solução definitiva para amenizar sua maior inquietação.

Neste sentido, Francisco de Oliveira descreve, do ponto de vista econômico, da reprodução do capital e dos custos da reprodução da força de trabalho, a transformação e a evolução do capitalismo urbano no Brasil e suas conseqüências para o trabalhador:

A aceleração [do crescimento industrial] afetará profundamente a relação salário real -custo de reprodução de força de trabalho urbana. No período de liquidação da economia pré anos 1930 esse conflito ou a equivalência dessa relação foi assegurada, de um lado, pela contribuição que a agricultura "primitiva" [grifo do autor] dava ao abastecimento das cidades e, de outro, pela reprodução nos contextos urbanos de certas formas de "economia de subsistência" [grifo do autor], das quais a construção da casa própria constituía importante parcela daquele custo. Sem embargo, a relação começa a desequilibrar-se no sentido de um salário real que não chega a cobrir o custo de reprodução, da força de trabalho, simplesmente pelo fato de que, não somente à medida que o tempo passa, mas à medida que a urbanização avança, à medida que as novas leis de mercado se impõem, o custo da reprodução da força de trabalho urbana passa a ter componentes cada vez mais urbanos: isto é, o custo de reprodução de força de trabalho também se mercantiliza e industrializa [...] enfim, todos os componentes do custo de reprodução se institucionalizam, se industrializam, se transformam em mercadorias. (OLIVEIRA, 2003, p. 84).

Chega-se então na origem do conceito da casa como mercadoria no Brasil, ou como este foi reproduzido no Brasil, e é na ideologia criada em torno da casa própria, alimentada pelo Estado com ações populistas - já que estas eram de seu interesse naquele momento - surgindo como aquele que se volta às preocupações e aflições populares, mas que também mantém o incentivo pela "tão sonhada casa própria", como forma de aquietar a insatisfação social e manter a hegemonia das classes dominantes, desviando a classe trabalhadora de maiores lutas políticas e sindicais.

A partir de então, toda a política pública habitacional foi formulada com base na obtenção da propriedade, consequentemente na aquisição da habitação, evidenciando ao longo destes anos que esta relação sempre foi desigual, pois a população que vive em cortiços, favelas, em habitações impróprias e sem qualidade, não foi alcançada em sua maioria pelos programas habitacionais, justamente porque a renda não é compatível com o valor da mercadoria, instaurando um jogo perverso de sedução - nos termos de incorporação de desejos e necessidades de Harvey (1998) - e de exclusão - nos termos de desequilíbrio de Oliveira (2003).

Com isso, percebe-se que o ato de morar tem um contexto político, social, econômico, espacial, psicológico e de classe, tendo o argumento ideológico da casa própria como elemento regulador destas tensões, sendo que o abrigo é uma necessidade do homem, da família, já a casa própria é um objeto de desejo que inclui o indivíduo e altera seu status na sociedade, a casa é objeto de consumo e a necessidade de morar fica alterada pela necessidade de obter.

É pela relação de sujeito-objeto tratada pelo prisma da interpretação que Leopold Waysbort (2000) realiza a partir das considerações de George Simmel, que se justifica a dinâmica do fetichismo que envolve a casa própria, onde abrigar-se passa a ser secundário e começa a imperar ter a moradia como sua propriedade, como forma de pertencer, de diminuir diferenças. ${ }^{4}$

Por este viés a necessidade do objeto torna-se secundária, mas predomina tê-lo para si, evidenciando "a preponderância do objeto sobre o sujeito" enquanto que o próprio objeto é resultado do sujeito.

Este pensamento produto da dialética da relação de sujeito que é vida, e objeto que é forma, ambos coexistindo como necessários e opostos, em que na tentativa de superação das diferenças - na aproximação - permanece a desconfiança - o afastamento. Waysbort (2000) identifica que Simmel "é consciente da dificuldade de reconciliação" na relação de sujeito e objeto, e esta consiste no que "é um ponto nodal em Simmel: os objetos são espíritos objetivados." (WAYSBORT, 2000, p.123) 
Harvey resume bem a relação que alimenta o fetiche na produção de mercadorias ao enfatizar que:

Na qualidade de produtores de mercadoria em busca do dinheiro, dependemos das necessidades e da capacidade de compra dos outros. Em conseqüência, os produtores têm um permanente interesse em cultivar "o excesso e a intemperança" nos outros, em alimentar "apetites imaginários" a ponto de as idéias sobre o que constitui a necessidade social serem substituídas pela "fantasia, pelo capricho e pelo impulso." O produtor capitalista tem cada vez mais "o papel de alcoviteiro entre os consumidores e seu sentido de necessidade, excitando neles apetites mórbidos, à espreita de cada uma de suas fraquezas - tudo isso para que se possa exigir o numerário pelo seu serviço de amor. " O prazer, o lazer, a sedução e a vida erótica são traduzidos para o âmbito do poder do dinheiro e da produção de mercadorias. (HARVEY, 1998, p.99)

5 Para esta questão ver MARK, K. (1964). "The economic and philosophic manuscripts of 1844". Nova lorque, p. 148

${ }^{6}$ Ver: BONDUKI, Nabil. Origens da Habitação Social no Brasil: Arquitetura Moderna, Lei do Inquilinato e Difusão da Casa Própria. São Paulo: FAPESP, 1998. MARICATO, Ermínia. Metrópole na Periferia do Capitalismo: ilegalidade, desigualdade e violência. São Paulo: Hucitec, 1996; e SACHS, Céline. São Paulo: Políticas públicas e habitação popular. São Paulo: EDUSP, 1999.
Harvey recorre neste momento à definição de Marx 5 ao afirmar que "o capitalismo 'produz de um lado, a sofisticação das necessidades e dos seus meios, e, de outro, uma bestial barbarização, uma completa, brutal e abstrata simplificação da necessidade" ", para depois prosseguindo, afirmar que "o reforço do fetichismo surge da dinâmica da troca de mercado, onde a propaganda e a comercialização anulam todos os vestígios da produção em suas imagens". (Harvey, 1998, p.99)

A necessidade de habitar foi facilmente alterada pela necessidade de obter a casa, e o Estado foi em grande parte responsável pela disseminação desse conceito, ao favorecer uma política de habitação arraigada na obtenção da posse, embora não conseguisse provê-la na mesma dimensão que o conceito se propagou. Oliveira auxilia no entendimento desta incapacidade do Estado e da dinâmica salarial ao expor:

Sem embargo, a repressão salarial é um fato. Onde vai parar, pois, o superexcedente arrancado aos trabalhadores e a que fins serve dentro do sistema? Aqui se pré-esboça sinteticamente a resposta: 0 superexcedente, resultado da elevação do nível da mais-valia absoluta e relativa, desempenhará, no sistema, 'a função de sustentar uma super- acumulação', necessária esta última para que a acumulação real possa realizar-se, [grifo do autor] assim, em primeiro lugar, o superexcedente tem uma 'função política de contenção' [grifo do autor], para o que, necessariamente, reveste-se de características repressivas. Isto é, torna-se indissociável a política da economia, porque a contenção da classe trabalhadora se faz, principalmente, pela contenção dos salários. (OLIVEIRA, 2003, p.100)

Assim, a forma como o capitalismo industrial se desenvolveu localmente, fincado na redução da capacidade salarial dos trabalhadores, alimentou a tensão desta dinâmica e diante do impasse, a classe trabalhadora desejosa da casa própria, com salários insuficientes para obtê-la, devido aos altos preços da produção habitacional que pela lógica capitalista não dispensa lucros, se vê obrigada a realizar seu desejo na forma que Ihe é possível, buscando uma saída para o jogo perverso.

Ou seja, mesmo tendo um trabalho formal e uma renda, o trabalhador vê-se obrigado a lançar meios próprios e movimentar-se no sentido de obter sua moradia a qualquer custo. Em razão disso, uma importante quantidade de residências da população foi construída através da autoconstrução, que é aquela produzida pelos próprios proprietários em dias de folga do trabalho e nos finais de semana, e outra parte através de mutirão que é a forma de cooperação entre um grupo de pessoas. Estas foram as soluções encontradas por grande parte da população à margem dos programas habitacionais, praticadas ao longo das últimas 7 décadas, em busca da realização do desejo da casa própria.

O item habitação resultante da autoconstrução e dos mutirões, produzida por trabalho não pago, compôs o custo da reprodução de força de trabalho e contribuiu para enfraquecer os salários pagos pelas empresas e desta forma, visão compartilhada por Bonduki (1998), Maricato (1996) e Sachs (1999)6, dedicados ao estudo da questão habitacional, remetem à compreensão sobre a autoconstrução, resumida por Oliveira, como sendo:

Uma operação que é na aparência, uma sobrevivência de práticas de "economia natural" [grifo do autor] dentro das cidades, casa-se admiravelmente bem 
com um processo de expansão capitalista, que tem uma de suas bases e seu dinamismo na intensa exploração da força de trabalho. (OLIVEIRA, 2003, p.59)

O que passa a nos importar então, é refletir sobre as conseqüências de uma política habitacional que não foi capaz de favorecer o acesso à moradia para a população de baixa renda, que a empurrou para a autoconstrução, método mais utilizado no Brasil, em sua maioria com baixa qualidade técnica e construtiva incorrendo em baixa qualidade das condições de habitabilidade, porém o único modo que permitiu que grande parte da população estivesse, pelo menos por algum tempo, abrigada.

Dentre os programas de política pública habitacional já implantados no Brasil, em que pesem outras experiências, o mais representativo, e que interessa tratar nesta consideração, em função daquilo que ainda implica atualmente, foi aquele implantado pelo Banco Nacional de Habitação (BNH) com recursos oriundos do Sistema Financeiro de Habitação (SFH). Significativo, certamente não pela qualidade, ou pelas características financeiras/ mercadológicas, mas, sobretudo pela quantidade de unidades habitacionais produzidas.

${ }^{7}$ Harvey considera que a acumulação flexível ainda é uma forma de capitalismo em que se pode esperar que algumas proposições básicas se mantenham. Das proposições extrai alguns elementos fundamentais da argumentação feita em The Limits to Capital (1982) e refere-se em especial à três características do modo capitalista de produção. (HARVEY, 1998, p.16466)
Na concepção do SFH estava explícita a intenção de resguardar o valor real da prestação, o retorno dos recursos captados e a lucratividade, pois desde a sua criação em 1964, estava previsto que sob os financiamentos concedidos para a produção de habitação, seria aplicada a correção monetária: um mecanismo de compensação inflacionária que permitia reajustar os débitos e as prestações por índices correspondentes à taxa de inflação. Desta forma, segundo Maria Silvia Barros Lorenzetti “Isto significa tratar a habitação como uma mercadoria a ser produzida e comercializada nos moldes capitalistas, presumindo que os adquirentes poderiam arcar com os custos da operação". (LORENZETTI, 2001, p.17)

Ao longo dos anos, a prática demonstrou uma incompatibilidade na intenção conceitual, em que a baixa capacidade de pagamento das famílias de menor renda, associada aos salários achatados pelo sistema inflacionário e arrocho salarial, não acompanhavam o reajustamento periódico das prestações e dos saldos devedores. A diferença entre o poder aquisitivo dos adquirentes e o valor das prestações foi agravada pela recessão econômica vivida nas décadas subseqüentes aos anos de 1970, e revelou um ponto nodal do financiamento habitacional praticado, que consistia no elevado número de contratos inadimplentes e na dificuldade de viabilizar financeiramente a continuidade dos programas.

A intervenção do Estado na produção de habitação através do BNH esteve baseada no sistema de propriedade do imóvel e não considerou a diferença entre o alto custo do investimento que envolve o preço do terreno, o aporte necessário para a infraestrutura, e o poder aquisitivo da clientela, que na maioria das vezes possui renda muito próxima do limite de sobrevivência, o que de imediato excluiu uma imensa parcela da população inserida no déficit habitacional do atendimento da provisão de moradia e, também, gerou inúmeros outros problemas baseados na inadimplência. Com isso o sistema não teve condições de crescer e, muito menos, de se expandir, entrando em crise e posterior colapso.

Acerca disso, Harvey, ao resumir a argumentação feita em reflexões sobre as três características essenciais do modo capitalista de produção, ${ }^{7}$ que mesmo não tendo por base o $\mathrm{BNH}$, aplicam-se a ele, observa que:

O capitalismo é orientado para o crescimento. Uma taxa equilibrada de crescimento é essencial para a saúde de um sistema econômico capitalista, visto que só através do crescimento os lucros podem ser garantidos e a acumulação do capital, sustentada. Isso implica que o capitalismo tem de preparar o terreno para uma expansão do produto e um crescimento em valores reais (e, eventualmente, atingi-los), pouco importam as consequências sociais, políticas, geopolíticas ou ecológicas. Na medida em que a virtude vem da necessidade, um dos pilares básicos da ideologia capitalista é que o crescimento é tanto inevitável como bom. A crise é definida, em consequência, como falta de crescimento. (HARVEY, 1998, p.164)

As considerações expostas pressupõem a existência de uma classe trabalhadora, entretanto, é vital reconhecer a transformação deste conjunto ao longo 
8 O PAR seleciona o interessado mediante a aprovação da análise cadastral em consulta ao Serviço de Proteção ao Crédito - SPC e SERASA, empresas com especialidade em análise e informações para decisões de crédito. das décadas e em especial admitir que esta dinâmica teve alterações profundas espelhadas no momento atual, chegando a dissolver ou no mínimo redistribuir os trabalhadores, refletindo na alteração das relações de trabalho que resulta no crescente aumento da informalidade como atividade de trabalho. Reflexo desta transformação é a vulnerabilidade dessa "massa" - deste conjunto de trabalhadores - em auferir uma renda invariavelmente insuficiente para compensar a falta de benefícios que, mesmo parcos, a relação de trabalho formal ainda mantém.

O desenvolvimento destas questões dão pistas de que o problema da habitação se concentra na visão de habitação como mercadoria, suscetível aos efeitos do capitalismo, em que nem o fato de sua aquisição ser cercada de mecanismos de retorno financeiro, garantem a continuidade dos programas, tampouco garantem o atendimento da população de baixa renda. O resgate da origem da disseminação do conceito da casa própria é extremamente importante para a compreensão da questão, mas o que parece saltar aos olhos, é que as políticas públicas voltadas para a aquisição da habitação reforçam o fetiche da casa própria, que vários estudos apontam como inacessíveis para a população de menor renda. Alimentar a concepção de habitação como sendo um objeto desejado, imbuido do sentimento de posse, não tem contribuido para minimizar o problema do déficit habitacional.

De todos os programas habitacionais implementados pelo poder público no âmbito do governo federal, apenas o Programa de Arrendamento Residencial (PAR) difere do modelo tradicional de aquisição da casa própria através do financiamento, pois sua origem - baseada no sistema de arrendamento francês - traz a concepção de uma operação de locação, em que o imóvel é de propriedade da CAIXA, em nome do Fundo de Arrendamento Residencial (FAR), exclusivamente criado para permitir a viabilidade financeira da operação e a segregação patrimonial e contábil dos bens financeiros e imobiliários do Programa. A composição dos recursos do FAR provenientes de recursos onerosos e não onerosos, permite praticar a política de subsídio na produção da habitação, atribuindo ao arrendatário, durante o tempo de arrendamento, efetuar a contrapartida através do pagamento da taxa de arrendamento, pelo tempo determinado por contrato de arrendamento.

Porém, a adesão deste programa por parte da população de baixa renda, a princípio, mostrou-se lenta à exemplo dos empreendimentos implantados em Marília, interior do Estado de São Paulo, e os motivos da baixa adesão podem residir, entre outros, principalmente na insuficiência de renda mínima estabelecida pelo Programa e pelo não atendimento das condições de crédito na análise cadastral. ${ }^{8}$ Contudo, não se pode afirmar que a adesão, inicialmente lenta, tenha ocorrido exclusivamente pelo fato da aquisição ser secundária, o que demonstra que o programa estaria interferindo na dinâmica que caracteriza o conceito de casa própria e abrindo frente para uma nova forma de confrontar a carência habitacional, remetendo a questão da propriedade de fato para segundo plano.

A pesquisa realizada com moradores do empreendimento, com resultados abordados sob diversos aspectos na dissertação de mestrado " $\mathrm{A}$ casa [própria] alugada no Programa de Arrendamento Residencial: questões da política pública habitacional e o caso do Residencial Cavalari em Marília/SP", entre outras considerações, sugere que passos largos em direção a uma aceitação por parte da população para a aderência às novas formas de acesso à moradia está em curso, corroborado pela destinação de recursos financeiros cada vez mais crescentes para a execução do PAR em diversas modalidades, incluindo vultosos recursos para construção de imóveis em locais atingidos por calamidades.

Quanto ao nível de entendimento da diferença entre financiamento e arrendamento, das conseqüências da inadimplência e da prática de vender, alugar ou ceder o imóvel arrendado, situações que culminam no desfazimento do contrato firmado entre a CAIXA e o arrendatário, e que de certa forma procura resguardar o equilíbrio financeiro do Programa, os dados resultantes da citada pesquisa realizada no interior paulista, apresentam-se favoráveis, induzindo a uma leitura que denota que os arrendatários estão devidamente esclarecidos diante da opção pelo arrendamento e das conseqüências do descumprimento do contrato de arrendamento. No aprofundamento da questão em entrevistas, 


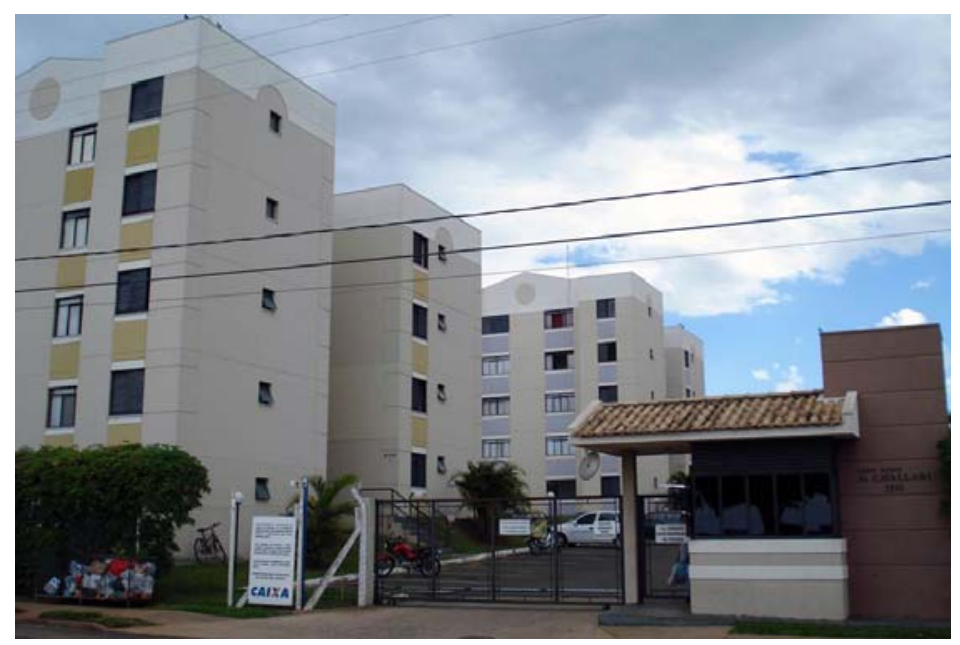

Figura 1: Residencial Cavalari, empreendimento do PAR em Marília/SP, reproduz os elementos que caracterizam os condomínios da classe média, com portaria e portão eletrônico, que conferem sensação de segurança aos moradores. Fonte: Ana Cristina da Silva Araujo. de um modo geral, esta supremacia permaneceu, no entanto, quando aprofundamos o diálogo e principalmente quando a questão da aquisição ao final do prazo contratual entrava em pauta, muito em função das iminentes mudanças da possibilidade da aquisição antecipada (da qual alguns arrendatários mostravam-se também conhecedores, embora ainda estivessem em trâmite no âmbito legislativo e com normatização a ser definida), anunciadas ao mesmo tempo em que a pesquisa em campo se realizava, algumas outras questões emergiram. Ao adentrar na diferença entre financiamento e arrendamento, e reforçar que a aquisição pela lei vigente na época só ocorreria ao final do contrato, o morador do residencial, denominado como Entrevistado 3 alega que:

Não, essa diferença não sabia não. Mas também se soubesse não vinha ao caso na época, porque quando eu corria atrás de pegar uma casa de BNH ou que seja, da CAIXA, nunca conseguia ser contemplado. Nessa aqui dei sorte de ser chamado, porque um amigo que trabalha comigo, conhece um vereador, deu uma força lá e levou uma ficha pra mim e acabei sendo chamado, aí coube a documentação fiz tudo. Quando vim pra cá, tinha só uns cacarecos. Depois que a gente pega isso aqui parece até que a gente se anima mais, até $o$ dinheirinho de um chiclete a gente pega e compra uma coisa. Se você tá lá [na casa que morava antes], não ia fazer tudo isso porque não aparece. Por um lado deu uma vida diferente, uma vida nova, de uma situação financeira fraquinha, dá pra fazer o que não tava fazendo antes. (ENTREVISTADO 3, 2007).

O depoimento remete a aquisição a um segundo plano, diante do efetivo ingresso no Programa, depois de incursões fracassadas nas tentativas de acesso em outros programas. Ainda que transpareça a suposição do entrevistado aludindo ao vereador o mérito por ter sido chamado para apresentar a documentação, mantém-se a necessidade de primeiro inscrever-se no programa, após seleção prévia, apresentar a documentação necessária e submeter-se à avaliação de cadastro realizada pela CAIXA. O que a declaração acrescenta para além do que a pesquisa pôde medir, refere-se à satisfação que o arrendatário experimenta, diante de um imóvel novo, servindo de estímulo para a aquisição de alguns móveis e com sinais legítimos de melhoria da qualidade de vida.

A crença da maioria (72\%) dos arrendatários pesquisados, quanto à retomada do imóvel mediante o descumprimento do contrato de arrendamento, 
também foram verificadas no âmbito da pesquisa, e na visão do arrendatário, denota que:

É só a regra que é diferente. Para a CAIXA tirar uma pessoa que tem um financiamento é muito mais difícil que uma pessoa do PAR. O PAR segue um outro tipo de regra. É rapidinho. Em três meses e já vai processo. (ENTREVISTADO 5, 2007)

Refere-se aos procedimentos jurídicos iniciados tão logo seja constatada a inadimplência, configurada pelo não pagamento de três parcelas consecutivas da taxa de arrendamento. A aplicação da decisão jurídica foi acompanhada pela esposa que complementa:

Vai para processo, o processo dura uns dois meses, aí o juiz ainda dá 24 horas pra acertar os 5 meses. Se você tiver, você ainda fica, continua. Quer dizer: você ainda tem essa regalia. Mas eu acho que a pessoa que não tem uma, duas parcelas, em 24 horas não vai ter 5 meses pra pagar com juros e tudo. Eu já vi, ele não, mas eu já e perguntei: 'aquele morador tá mudando e disseram: é, ele perdeu o apartamento'. Então, nem sei quem é, só vi o caminhão de mudança saindo, então quer dizer que eles cumprem mesmo. (ENTREVISTADA 6, 2007)

O depoimento confirma a celeridade da ação jurídica que envolve a retomada do imóvel mediante descumprimento do contrato, reafirma as constatações anteriores que residem no fato de que uma intervenção firme relacionada à retomada, leva à consciência de que o cumprimento das regras básicas do arrendamento deve ser priorizado, na medida do possível.

O último conjunto de resultados, apresentado na

${ }^{9}$ Dados obtidos em março de 2007, em consulta à CAIXA, Agência de Marília, no setor de Habitação. Refere-se ao financiamento na modalidade carta de crédito individual, para efeito deste exemplo, sem uso do FGTS como recurso próprio. citada pesquisa, expressa que a motivação do pesquisado para a adesão ao arrendamento, corrobora grande parte dos temas que tratamos naquele estudo. Ao resgatar os principais motivos que levaram estes arrendatários a optarem pela modalidade do arrendamento de modo prevalecente ao financiamento, 35\% das respostas incidiram sobre a consideração de que o valor definido para a taxa de arrendamento era menor que o de um financiamento. Em segundo lugar, 24\% das respostas revelam que a opção pelo arrendamento deve-se ao fato de que o valor da taxa de arrendamento era menor que o valor pago em aluguel praticado pelo mercado imobiliário. Não auferir renda suficiente para ser enquadrado nos financiamentos disponíveis, foi motivação para que $17 \%$ de nossa amostra optassem pelo arrendamento. Motivos menores e diversos foram relatados sem constituir relevância maior do que os já apresentados.

Neste sentido, ultrapassando os limites de uma questão quantitativa, depreendemos que algumas considerações dos arrendatários confirmam nossa pesquisa. O Entrevistado 3 acrescenta em relato outro fator para a motivação pela opção de arrendamento:

"Aqui não teve que depositar nada. Esse foi o nosso lado, você entendeu o que pescou a gente aqui dentro? Nós entramos com uma parcela, só. Não tivemos que entrar com nenhum dinheiro." (ENTREVISTADO 3, 2007)

Sintetiza um fator que é incidente da operação de financiamento, referindo-se aos financiamentos concedidos em limite de até $80 \%$ do valor do imóvel, sendo que os $20 \%$ restantes cabem ao futuro mutuário como contrapartida, que além de dispor deste montante, tem que desembolsar e depositar em conta na CAIXA, um valor destinado para pagamento do registro de contrato. Para imóveis financiados com valor limitado a $R \$ 38.000,00$, para uma renda familiar de até $R \$ 1.800,00$, em prestações mensais de cerca de $R \$ 380,00$ pagas em 20 anos, dependendo da análise de renda e de capacidade de pagamento do interessado, a CAIXA concede financiamento de $100 \%$ para imóveis novos (com habite-se até 6 meses), mediante um depósito de cerca de $\mathrm{R} \$ 2.700,00$ para despesas com documentação. ${ }^{9}$ Neste mesmo caso, para imóveis usados ou para imóveis com valor de venda acima deste, exige-se a contrapartida de $20 \%$ do valor do imóvel, como recurso próprio.

Tal contrapartida e o depósito para despesas de documentação intrínsecos ao financiamento, não são incidentes no arrendamento, com isso, de fato, o programa "pesca" aqueles que substituem o aluguel pelo arrendamento, com o atrativo de não 
incidir em mais despesas, além da própria taxa de arrendamento e, neste caso, da taxa condominial.

Não faltaram justificativas a favor da opção pelo arrendamento, mas destaca-se que:

"Não quisemos fazer financiamento, porque na época surgiu esse plano do PAR, tudo encaixou pra nós, saímos do aluguel, por causa do preço da parcela também, por causa do local. Não é no centro, mas a localidade é melhor do que os outros [...] Na época eu não procurei financiamento. Quando surgiu isso do PAR me interessou. Eu fui direto e me interessou." (ENTREVISTADO 5, 2007)

Quando remetemos ao entendimento da motivação pela adesão ao arrendamento, descolada da comparação com o financiamento, com base nos resultados de outra questão aplicada na pesquisa, verificamos que ter uma casa própria, diminuir o valor pago com aluguel, melhorar as condições de vida, sair da casa dos pais e morar em um imóvel melhor, são pela ordem, as respostas mais incidentes em nossa mostra, remetendo a opção de desfazer a situação de aluguel como menos prevalente. Encontramos uma possibilidade que, de certa forma, justifica esta menor prevalência, e refere-se ao fato de que os arrendatários não consideram que ao aderir ao arrendamento, saíram totalmente da situação de aluguel.

Admitindo a intenção de adquirir o imóvel ao final do contrato de arrendamento, outra questão abordada, prática que o contrato de arrendamento garante desde que não exista inadimplência e conseqüentemente rompimento do contrato, a pesquisa revela que chegar ao final do contrato, cumprindo as exigências que os mantenham como prováveis adquirentes e desta forma alcancem esse intento, ter finalmente uma casa própria ao final do contrato é a motivação que compõe $57 \%$ da mostra, seguido de $29 \%$ que almejam a aquisição por considerarem que é um investimento e, ao final do prazo, poderão dispor do imóvel da forma que Ihes convier. Neste sentido, projetam a obtenção da casa própria para longo prazo. Esta mostra permite concluir que o conceito de casa própria não é totalmente afastado e que dissolver as agruras da busca por um imóvel que se adéqüe às suas condições, seja pela procura fracassada de inserir- se em financiamento, seja por cessar a submissão aos altos aluguéis ou por cessar a submissão ao habitar moradias em condições impróprias; abarca ainda considerações como: "Quando cheguei em Marília não conhecia ninguém e nunca conseguia alugar um imóvel que prestasse porque não tinha fiador, fica difícil arranjar as coisas sem fiador" (Pesquisado 5, 2007). Pela falta de fiador, foi morar no Alto Cafezal, bairro próximo do Centro, parte antiga da cidade, em um trecho conhecido por Morro do Querosene, antigo reduto de prostituição durante a noite, e com presença de barracões de oficinas mecânicas, serralherias e outros serviços ruidosos de funcionamento diurno.

Atualmente a área não é mais reduto de prostituição, sendo um local deserto durante a noite. Além dos barracões, é constituído de habitações precárias, construídas em lotes que ficam até três metros abaixo do nível da rua, em casas originalmente de madeira, sendo que algumas possuem ampliações igualmente precárias, por vezes em alvenaria.

O último conjunto de resultados da pesquisa consolida a noção do arrendamento como possibilidade de rompimento do paradigma da casa própria, remetendo a aquisição para longo prazo. Entretanto é no depoimento do arrendatário que tal afirmação ganha expressão:

"A gente saiu de uma casa de madeira e veio pra cá pra ter um futuro um pouquinho melhor, um lugarzinho mais adequado pra gente num futuro, pra ficar velho, já pensou se ficar num lugar bem desconfortável? Mas pelo menos saímos de uma coisa que a gente tava em condições ruins, não era meu, não tava em meu nome, nada... Era de madeira, lugar bem antigo." (ENTREVISTADO 3, 2007)

Os resultados e a análise da pesquisa com os arrendatários expressos pelos dados acima, certamente não expõem a totalidade, tampouco a dimensão abrangente da pesquisa realizada, entretanto cumprem papel secundário de abrir senda para uma variada gama de interpretações e análises decorrentes de nossa opção primordial pelo apego à síntese, necessário para que as questões prevalentes deste estudo fossem destacadas. 
Figura 2: Bairro consolidado antes mesmo da construção do empreendimento, implantado em uma quadra cuja lateral é ocupada por residências para estudantes e cercado por comércio e serviços básicos. Fonte: Ana Cristina da Silva Araujo.

Figura 3: Constituído por blocos interligados de cinco e quatro andares, dependendo da topografia, o padrão estético do empreendimento difere dos conjuntos habitacionais da cidade destinados à mesma faixa de renda dos adquirentes do PAR. Fonte: Ana Cristina da Silva Araujo.
De positivo do arrendamento residencial, depreende-se pelo estudo de caso do Residencial Cavalari, o apontamento de que a secundarização da propriedade pode ser alternativa para a minimização dos efeitos excludentes da tradicional política de financiamento calcada na obtenção da posse.

Por fim, e voltando à origem da inquietação que provocou este estudo acadêmico, a casa (própria) alugada do Programa de Arrendamento Residencial, representa e concentra os conceitos que movem grande parte da população brasileira em busca de uma casa, neste caso, ainda nem tão própria, questão que se torna secundária diante dos altos aluguéis e da necessidade de habitar, como confirma a simplicidade resumida na observação de um dos muitos colaboradores deste estudo:
Era isso aqui mesmo! Não tinha pra onde correr, ou pega ou larga! Veio na hora certa. Já ouviu falar que na hora da fome o pão duro é mais gostoso? Muito mais gostoso! (ENTREVISTADO 3, 2007).

Em que pesem ainda deficiências na concepção e implementação do PAR, os resultados da pesquisa no Residencial Cavalari revelam através da percepção dos arrendatários, que a crença nos rápidos mecanismos de cerceamento da inadimplência, representa um novo posicionamento, e fator a favor da manutenção e continuidade do Programa; aspecto fundamental que pode consolidar novos rumos para a política pública habitacional calcada também na modalidade de arrendamento.

Por outro lado, o incentivo ao avanço tecnológico adequado à realidade brasileira, visando a utilização
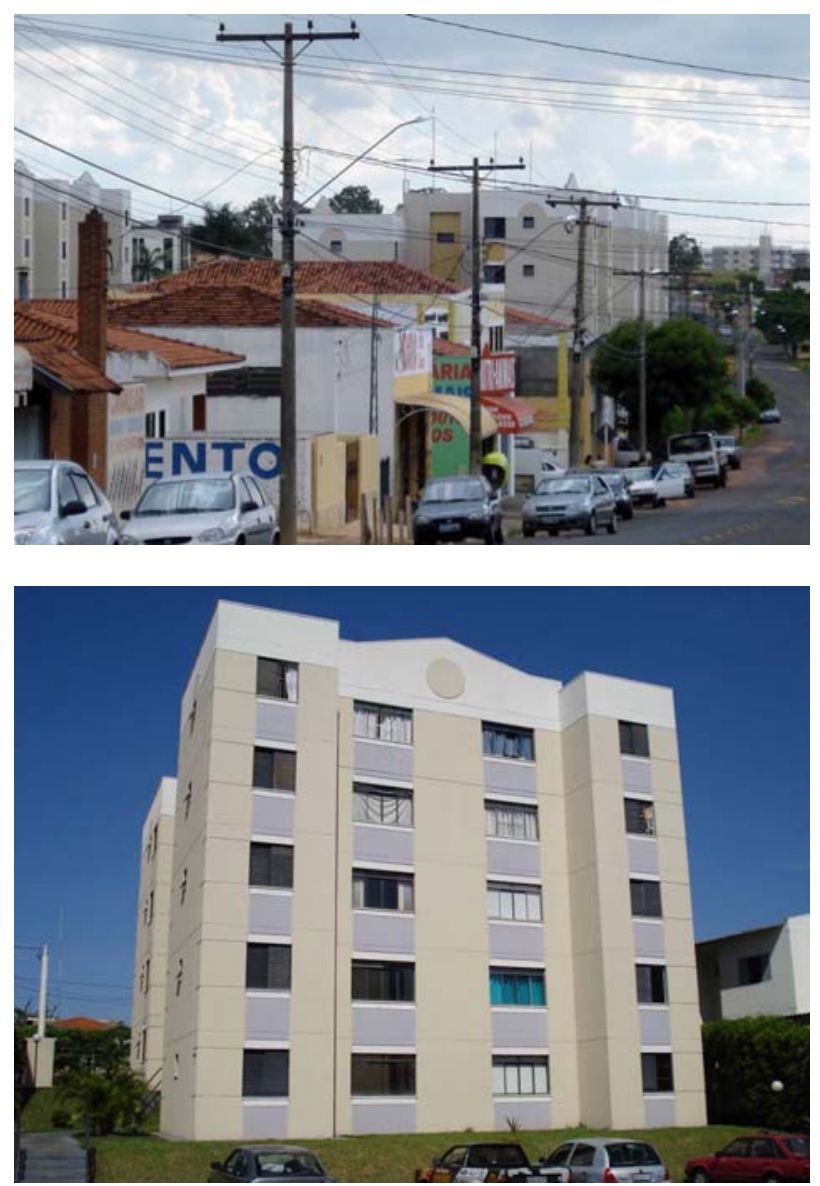
${ }^{10}$ Martha Ferreira Santos Farah (1996) identifica as estratégias de adaptação à crise da moradia nas grandes cidades brasileiras sob a ótica do processo de trabalho na construção habitacional, descrevendo e analisando os processos construtivos que buscam a racionalização e a dinâmica do trabalho operário que tais alternativas alteram. de materiais e sistemas construtivos mais baratos e com bom desempenho, além da consolidação de inovações no processo produtivo rompendo paradigmas na relação de trabalho, em uma dinâmica já apontada por Martha Ferreira Farah (1996), constituem questões que ainda são preeminentes na esfera habitacional social brasileira ${ }^{10}$, assim como são preeminentes os aparatos legislativos que introduzissem mecanismos de isenção fiscal e de incentivo à produção de habitação voltada para o atendimento das famílias de baixa renda.

A habitação é uma mercadoria de produção trabalhosa, requer cuidado quanto ao método construtivo e a qualidade construtiva, quanto à localização que faz incidir outros custos sobre o seu valor; é construída sobre um dos mais caros bens que é a terra urbana, tendo um parco desenvolvimento da indústria civil voltada para a produção em larga escala - já comprometida pelo preço da terra - e para colaborar com o cenário, invariavelmente cara e inacessível para a população carente. Comparada a bens de consumo como roupas, sapatos, alimentos, móveis, e até mesmo ao automóvel, a casa é a mercadoria mais cara, com prazos para pagamento que chegam a até 20 anos, tendo em sua política de financiamento diferenças relacionadas entre o valor de venda e a capacidade de pagamento dos adquirentes.

Diante deste cenário as características relacionadas à modalidade de arrendamento podem conjugar ou desfazer tensões que a lógica do capitalismo imprime na operação de financiamento e na forte disseminação do conceito de casa própria.

Nesse sentido torna-se vital para a política habitacional que esteja alinhada com a política urbana e articulada com o desenvolvimento e planejamento das cidades, deste modo é possível minimizar o alto custo da terra proveniente da especulação que incide no valor do produto sobre o que nela é construído: a casa.

Sendo assim, a luta, o esforço cantado na "casa do reagge" que abriu parte desta reflexão, poderia inexistir ou até mesmo ser canalizado para outras conquistas, menos ou até mais árduas, caso a habitação deixasse de ser um objeto de consumo e de desejo, arraigado no sentimento de posse, que resume a necessidade e o sonho de uma vida inteira de grande parte da população brasileira, para finalmente tornar-se um direito à moradia digna.

O direito à moradia, resguardado pelos atos legislativos e referendado pelos fóruns nacionais e mundial de habitação, elevou a questão para o campo prioritário da ação pública, tendo os fenômenos da pobreza e precariedade a dar corpo para o consenso de que o acesso à moradia e a permanência nela configuram uma das dimensões essenciais de uma política de luta contra a exclusão. Atribui-se a questão da moradia como sendo de responsabilidade da nação em seu conjunto, ultrapassando a competência pura e simples do Estado.

O maior desafio do PAR reside exatamente no que o difere dos programas tradicionais, historicamente calcados na obtenção da casa própria através do financiamento. No entanto, a projeção da aquisição da unidade habitacional remetida para o final do contrato de arrendamento, parece ter eliminado a necessidade de disseminar novos conceitos ou, no mínimo, de se preocupar com demais medidas que confrontassem com o paradigma da casa própria; a possibilidade da antecipação, medida em curso, apenas reforça uma aceitação que já estava instalada.

Além disso, se por um lado o conceito da casa própria foi insistentemente disseminado junto à população brasileira, por outro lado a política habitacional se mostrou sistematicamente incapaz de fornecer moradias em número suficiente para combater o déficit, significando para a população brasileira grande dificuldade e muitas vezes a impossibilidade de acessar a casa própria. Ao longo das décadas, a população à margem do sonho da casa própria, acostumou-se ao penoso sistema de locação imposto pelo mercado imobiliário e às demais formas de moradia barata. A necessidade de habitar em condições dignas e de modo condizente com os rendimentos da população carente parece ter caminhado em paralelo com o desejo de obtenção da casa própria.

Na medida em que se defende o PAR como real possibilidade de combate ao déficit habitacional 
brasileiro na modalidade de construção, ou ainda como programa que dá suporte financeiro e operacional ao Programa de Recuperação de Sítios Históricos (PRSH), atuando na promoção da revitalização de sítios históricos por meio de ações que buscam integrar preservação de patrimônio, desenvolvimento urbano e revitalização de áreas centrais, destacando o componente habitacional como principal estimulador do patrimônio urbano e cultural, admitindo parcerias internacionais, a exemplo da parceria do Governo Francês com o Ministério das Cidades; quando se admite o programa como importante instrumento na articulação de uma política pública, que permite privilegiar a ocupação de lotes remanescentes, consequentes da prática de ocupação desordenada produtora de vazios urbanos, recompondo o tecido urbano; então já não se admite mais escapar da busca e do entendimento de sua base conceitual: o sistema de locação social francês, sob o prisma de enriquecer as diretrizes e na intenção do fortalecimento do arrendamento residencial brasileiro. Como também já não se admite mais focar os estudos acerca da questão habitacional sem, doravante, considerar o papel da locação social como importante instrumento de política pública habitacional.

\section{Referências bibliográficas}

BARREIRA, Maria. Cecília Roxo Nobre; CARVALHO, Maria do Carmo Brant (orgs). Tendências e perspectivas na avaliação de políticas e programas sociais. São Paulo: IEE/PUC-SP, 2001

BLAY, Eva A. Eu Não Tenho Onde Morar - Vilas operárias na cidade de São Paulo. São Paulo: Nobel, 1985.

BONDUKI, Nabil. Habitar São Paulo: reflexões sobre a gestão urbana. São Paulo: Estação Liberdade, 2000.

BONDUKI, Nabil. Origens da Habitação Social no Brasil: Arquitetura Moderna, Lei do Inquilinato e Difusão da Casa Própria. São Paulo: FAPESP, 1998.

BONDUKI, Nabil. Habitat - As práticas bem-sucedidas em habitação, meio ambiente e gestão urbana nas cidades brasileiras. (org.). São Paulo. Studio Nobel, 1996.

BONDUKI, Nabil; BUZZAR, Miguel A. (coord.) Elaboração de Metodologia de Avaliação dos Programas Habitacionais e de Saneamento Financiados com
Recursos do FGTS no Estado de Minas Gerais, 1999/2002. Depto. de Arquitetura e Urbanismo da EESC USP e FIPAI. Coordenação: Profs.Drs. Nabil G. Bonduki e Miguel Antonio Buzzar. (12 Relatórios vários volumes).

BUZZAR, Miguel Antônio. (org). Aplicação de Metodologia de Avaliação dos Programas Habitacionais e de Saneamento Financiados com Recursos do FGTS no Estado de Minas Gerais: Departamento de Arquitetura e Urbanismo da EESC USP e FIPAI,2003/2004.

FARAH, Marta ferreira dos Santos. Processo de trabaIho na construção habitacional: tradição e mudança. São Paulo, Annablume, 1996.

HARVEY, David. Condição Pós Moderna. Tradução de Adail Ubirajara Sobral, Maria Stela Gonçalves. São Paulo: Edições Loyola, 1989.

KOWARICK, Lúcio F. F. A espoliação urbana. Rio de Janeiro: Paz e Terra, 1979.

KOWARICK, Lúcio F. F. Lutas sociais e a cidade. de São Paulo: passado e presente. Rio de Janeiro: Paz e Terra, 1994

LORENZETTI, Ma . Silvia Barros. A questão habitacional no Brasil. Consultoria Legislativa da Câmara dos Deputados. Estudo de julho de 2001. Relatório apresentado com base em monografia final do curso de Especialização em Políticas Públicas da EEPG/UFRJ, em 1998 e em artigo publicado na Revista da ASLEGIS. Disponível em:<www2.camara.gov.br/publicacoes/estnottec/ tema14/107075.pdf> Acesso em: 18/05/2006.

MANTEGA, Guido. A Economia Política Brasileira. São Paulo/Rio de Janeiro: Polis/Nozes, 1984.

MARICATO, Ermínia. Habitação e Cidade. São Paulo: Atual, 1997.

MARICATO, Ermínia. Metrópole na Periferia do Capitalismo: ilegalidade, desigualdade e violência. São Paulo: Hucitec, 1996.

MARICATO, Ermínia. Política Habitacional no Regime Militar. Petrópolis: Vozes, 1987.

MARICATO, Ermínia. Brasil, cidades: alternativas para a crise urbana. Petrópolis: Vozes, 2001.

OLIVEIRA, Francisco. Crítica à Razão Dualista - O Ornitorrinco. São Paulo: Boitempo Editorial, 2003.

ROLNIK, Raquel. A Cidade e a Lei: Legislação, política urbana e territórios na cidade de São Paulo. SãoPaulo: FAPESP/Studio Nobel, 1997.

SACHS, Céline. São Paulo: Políticas públicas e habitação popular. São Paulo: EDUSP, 1999.

WAYSBORT, Leopold. As Aventuras de George Simmel. São Paulo: Editora 34, p.: 11-358, 2000.

WERNA, Edmundo. et al. Pluralismo na habitação. São Paulo: Annablume, 2001 


\title{
A casa [própria] alugada: questões da política pública habitacional
}

Ana Cristina da Silva Araujo

\begin{abstract}
This article deals with the issue of residential rental as a possible way of reducing Brazilian housing deficit; it discusses the concepts found in the owned house paradigm and the contribution of an empirical research conducted in the Residencial Cavalari (Cavalari Residence), in the city of Marilia, State of São Paulo, Brazil, as a basis to understand the disruption of this form of social construct, which is rooted in the imaginary of the Brazilian population, due to the strong diffusion of the Residential Rental Programme.
\end{abstract}

Keywords: Residential rental, social tenancy, public housing policy. 